\title{
Relevance of Light Spectra to Growth of the Rearing Tiger Puffer Takifugu rubripes
}

\author{
Byeong-Hoon Kim ${ }^{1}$, Sung-Pyo Hur ${ }^{2}$, Sang-Woo Hur ${ }^{3}$, Chi-Hoon Lee ${ }^{1}$, and ${ }^{\dagger}$ Young-Don Lee $^{1}$ \\ ${ }^{1}$ Marine Science Institute, Jeju National University, Jeju 63333, Korea \\ ${ }^{2}$ Jeju International Marine Science Research \& Logistics Center, Korea Institute of Ocean Science \& Technology, \\ Jeju 63349, Korea \\ ${ }^{3}$ Aquaculture Management Division, National Institute of Fisheries Science, Busan 46083, Korea
}

\begin{abstract}
In fish, light (photoperiod, intensity and spectra) is main regulator in many physiological actions including growth. We investigate the effect of light spectra on the somatic growth and growth-related gene expression in the rearing tiger puffer. Fish was reared under different light spectra (blue, green and red) for 8 weeks. Fish body weight and total length were promoted when reared under green light condition than red light condition. Expression of somatostatins (ss 1 and $s s 2)$ in brain were showed higher expression under red light condition than green light condition. The ss 3 mRNA was observed only higher expression in blue light condition. Expression of growth hormone $(g h)$ in pituitary was detected no different levels between experimental groups. However, the fish of green light condition group was showed more high weight gain and feed efficiency than other light condition groups. Our present results suggest that somatic growth of tiger puffer is induced under green light condition because of inhibiting ss mRNA expression in brain by effect of green wavelength.
\end{abstract}

Key words : light spectra, somatic growth, somatostatin, growth hormone, tiger puffer

\section{INTRODUCTION}

In fish, light (photoperiod, intensity and spectra) is one of main environmental conditions on the regulation of numerous physiological actions including growth, feeding activity, migration and reproduction (Boeuf \& Le Bail, 1999; Migaud et al., 2010; Kim et al., 2013). Studies were conducted to find a suitable light conditions to promote the growth in farmed fish (Simensen et al., 2000; Kissil et al., 2001; Henne \& Watanabe, 2003; Taylor et al., 2005). In natural sea water, light spectra were distributed along the depth of water because water column act as a chromatic filter (Villamizar et al., 2011). Generally, red spectrum (long wavelength) is absorbed in the shallow water and blue spectrum (short wavelength) was predominated to deeper depth. According to presence of light wavelength with depth, fish physiological functions and habitat are adapted. However, in general aquaculture system, fish is reared under the shallow water depth and natural light or artificial white light conditions. Therefore, study is required on the appropriate light spectra conditions in fish aquaculture system. Recent studies were noticed that the light spectra affects in somatic

\footnotetext{
Manuscript received January 15, 2016, Received in revised form January 22, 2016, Accepted February 1, 2016

${ }^{\dagger}$ Corresponding Author : Young-Don Lee, Marine Science Institute, Jeju National University, 19-5, Hamdeok 5(o)-gill, Jocheon, Jeju 63333, Korea. Tel. : +82-64-782-8922, Fax: +82-64-782-8281, E-mail : leemri@jejunu.ac.kr

This is an Open Access article distributed under the terms of the Creative Commons Attribution Non-Commercial License (http:// creativecommons.org/licenses/by-nc/3.0) which permits unrestricted non-commercial use, distribution, and reproduction in any medium, provided the original work is properly cited.
} 
growth of teleost fish (Villamizar et al., 2009; Karakatsouli et al., 2010; Hyedamejad et al., 2013). However, these results of fish growth effect by light spectra were always not synchronized and it appeared the species specificity.

The tiger puffer Takifugu rubripes is a commercially valuable species in aquaculture industry of South Korea, China and Japan. However, effect of main environmental condition including light spectra on growth of tiger puffer is no information until now. The aim of the present study is to suggest an effective rearing conditions in tiger puffer aquaculture farm using the ability of light spectra adaptation. We investigate the impact of artificial different light spectra on the somatic growth the rearing tiger puffer and analyze the expression of growth-related genes in each brain and pituitary.

\section{MATERIALS \& METHODS}

\section{Fish and experimental design}

Tiger puffer for the present study were obtained from Tham-Ra Fishery located in Seogwipo, Jeju, South Korea and kept in rearing tank at Marine Science Institute, Jeju National University. Fish were reared under natural photoperiod and water temperature conditions in indoor tank and fed commercial pellets (Daehan co., MP3, Busan, South Korea) twice a day before starting experiment. After sufficiently adapted, fish ( $\mathrm{n}=120$, body weight $124.2 \pm 1.5 \mathrm{~g}$, total length $18.1 \pm 0.1 \mathrm{~cm})$ were divided into three groups; blue (480 $\mathrm{nm})$, green $(520 \mathrm{~nm})$ and red $(590 \mathrm{~nm})$ wavelength conditions. The light intensity of the blue, green and red were adjusted $150 \mathrm{~lx}$ and $15.2 \pm 1 \mathrm{ft}-\mathrm{cd}$ according to the previous methods (Hur, 2011). Experimental fish were reared during 8 weeks under natural water temperature $\left(10.8-12.5^{\circ} \mathrm{C}\right)$ and photoperiod was equated with natural photoperiod using a timer. The fish were fed commercial pellets twice a day during experimental period. Fish body weight (BW) and total length (TL) measured every 4 weeks. In during experimental periods, body weight gain, feed consumption and feed efficiency were calculated. Fish sampling was performed initial five fish and final six fish for each light condition groups. Sampled brain and pituitary tissues were immediately stored $-80^{\circ} \mathrm{C}$ until the analysis.

\section{Total RNA extraction and real-time qPCR}

Collected brain and pituitary tissues of the tiger puffer were absolutely homogenized with RiboEx ${ }^{\mathrm{TM}}$ (GeneAll, Seoul, Korea) reagent for total RNA extraction and total RNA was extracted following the manufacturer's protocol. Extracted total RNA with treated using RQ1 RNase-Free DNase (Promega, Madison, WI, USA). RNA concentration measured using the Nano Vue (GEHealthcare, Ver.1.0.1, UK) and $500 \mathrm{ng}$ of total RNA used in cDNA synthesis with PrimeScript RT reagent Kit (Takara Bio Inc, Otsu, Japan).

Synthesized cDNA 20 ng used for Real-time qPCR with Evagreen premix PCR kit (abm Inc, Canada). For real-time qPCR, primer sets of each genes were designed by isolated somatostatins (ss1, ss2 and ss3) and growth hormone ( $g h)$ of Takifugu rubripes from National Center for Biotechnology Information (NCBI, Table 1). Real-time qPCR was conducted by $\mathrm{CFX}^{\mathrm{TM}}$ Real-time System (Bio-Rad, Hercules, CA, USA)

Table 1. Primer sets used in this study

\begin{tabular}{ccc}
\hline \hline Primers & Sequence(5'-3') & $\begin{array}{c}\text { GeneBank } \\
\text { accession No. }\end{array}$ \\
\hline ss 1 -F & TCTGCTACTGCAGTCCAACG & XM_003968318 \\
ss $1-\mathrm{R}$ & CCTTCAGCCAGAGCAAGGTT & \\
\hline ss2-F & TGCATTCAGGGTGTGTCCTC & XM_003968317 \\
ss2-R & CAATCAGGTCCTCCACAGCA & \\
\hline ss3-F & ATGCAGCTTCTGGTGGTGTT & XM_003963129 \\
ss3-F & GAATCAGCTCCTTGCGCTCT & \\
\hline gh-F & CTCATCAAGGCCAGTCAGGAT & U63807 \\
$g h-\mathrm{R}$ & CTCCACCTTGTGCATGTCCT & \\
\hline efl- $\alpha-\mathrm{f}$ & GGCCTTCTCAAACCAAGCAT & AB193485 \\
ef2- $\alpha-\mathrm{f}$ & CCTTTGGTGGGTCGTTCTTG & \\
\hline & & \\
\hline
\end{tabular}


and amplification performed on the conditions: initial denaturation at $95^{\circ} \mathrm{C}$ for $10 \mathrm{~min}, 40$ cycles of $95^{\circ} \mathrm{C}$ for 15 sec, $60^{\circ} \mathrm{C}$ for $1 \mathrm{~min}$ and last $60^{\circ} \mathrm{C}$ for $1 \mathrm{~min}$. Growthrelated genes expression were normalized to the amount of the internal control ef1- $\alpha$ (elongation factor 1-alpha) gene (Table 1).

\section{Statistical analysis}

Real-time qPCR expression data was presented as mean \pm standard error (SEM) and considered significantly different at $P<0.05$. Statistical differences among means were analyzed by one-way analysis of variance (ANOVA) followed by Duncan's multiple range test.

\section{RESULTS}

\section{Fish growth}

We have measurement of fish BW and TL between experimental groups in every 4 weeks (Fig. 1). Initial fish BW was no different between three groups, but BW of green and blue light conditions groups were more increased than red light condition after 4 weeks. After that, BW of green light condition was steadily maintained significantly more high levels than red light condition until final weeks. The TL of fish was no differed between experimental groups after 4 weeks, but in final weeks, TL of green light condition was significantly increased than red light condition. In during experimental period, change of survival rate, weight gain and feed efficiency were shown in Table 2 . The fish
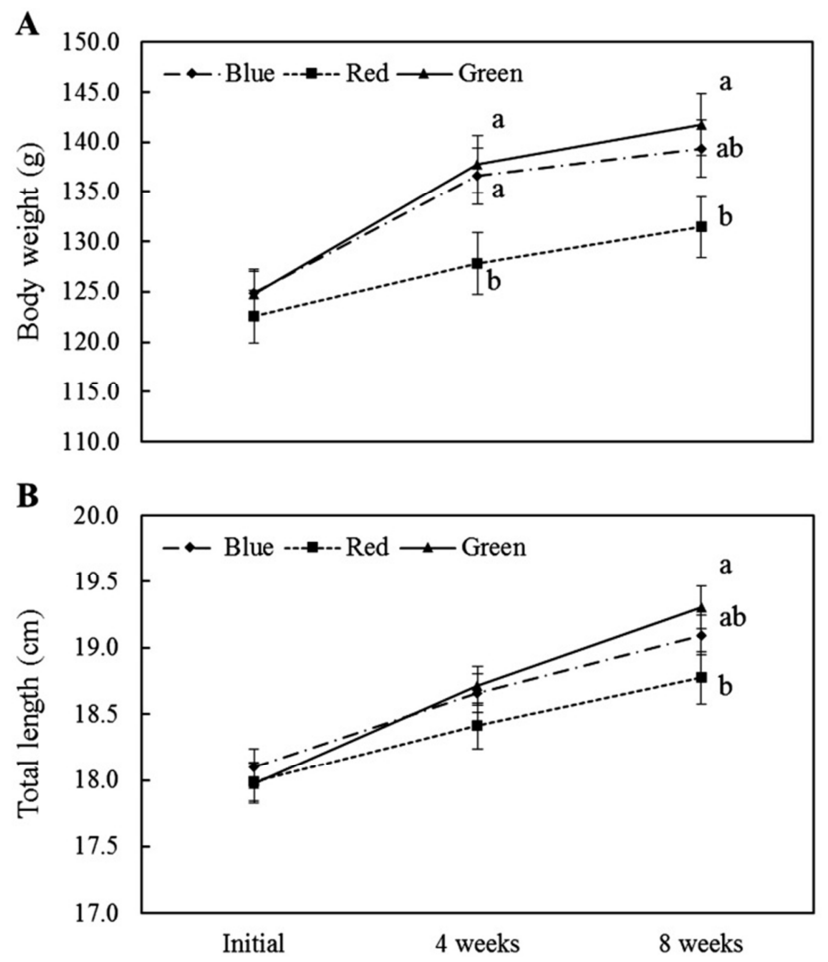

Fig. 1. Change of BW (A) and TL (B) during tiger puffer rearing under different light spectra (blue, red and green) conditions. Means represented by differrent letters are significant $(P<0.05)$. Values are mean \pm SEM.

in each light condition groups did not die during the experiment. The fish of green light condition group was showed more high weight gain and feed efficiency than other light condition groups.

\section{The mRNA expression of growth-related genes}

We profiled somatostatins ( $s s 1, s s 2$ and $s s 3$ ) and growth hormone $(g h)$ mRNA expression conducted by different light

Table 2. Growth performance and feed efficiency of tiger puffer rearing under different light spectra (blue, red and green) conditions for 8 weeks

\begin{tabular}{|c|c|c|c|c|c|c|c|}
\hline \multirow{2}{*}{$\begin{array}{l}\text { Experimental } \\
\text { group }\end{array}$} & \multirow{2}{*}{$\begin{array}{c}\text { Initial } \\
\text { Fish No. }\end{array}$} & \multicolumn{3}{|c|}{8 week } & \multirow{2}{*}{$\begin{array}{l}\text { Survival rate } \\
\quad(\%)\end{array}$} & \multirow{2}{*}{$\begin{array}{l}\text { Weight gain } \\
\qquad(\mathrm{g})\end{array}$} & \multirow{2}{*}{$\begin{array}{c}\text { Feed efficiency } \\
(\%)\end{array}$} \\
\hline & & Sum weight(g) & Fish No. & Sum weight(g) & & & \\
\hline Blue & 40 & 4,994 & 40 & 5,574 & 100 & 580 & 37.0 \\
\hline Red & 40 & 4,901 & 40 & 5,257 & 100 & 356 & 29.8 \\
\hline Green & 40 & 4,992 & 40 & 5,670 & 100 & 678 & 41.0 \\
\hline
\end{tabular}


A

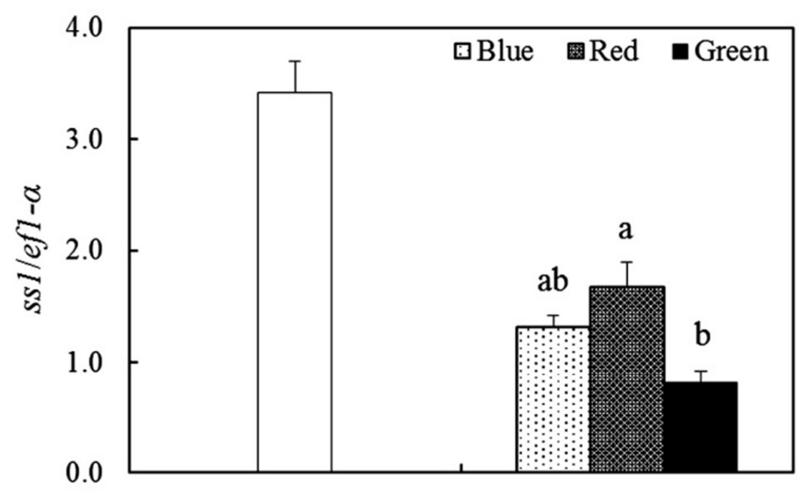

B

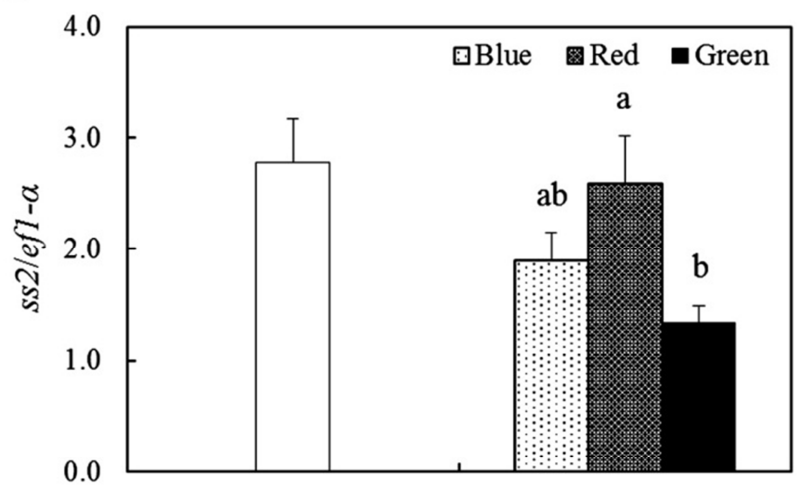

C

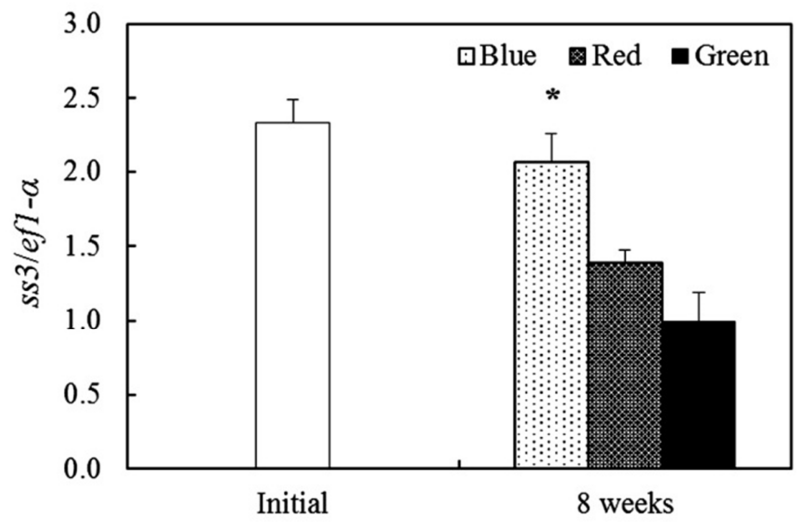

Fig. 2. ss1, ss2 and ss 3 mRNA levels in the brain of tiger puffer under different light spectra conditions (blue, red and green). Means represented by different letters are significant $(P<0.05)$. Values are mean \pm SEM.

wavelength in tiger puffer. After 8 weeks, the $s s 1$ mRNA of red light condition was shown significantly $(P<0.05)$ high expression than other experimental groups and $s s 1$ mRNA expression of green light condition was lowest than

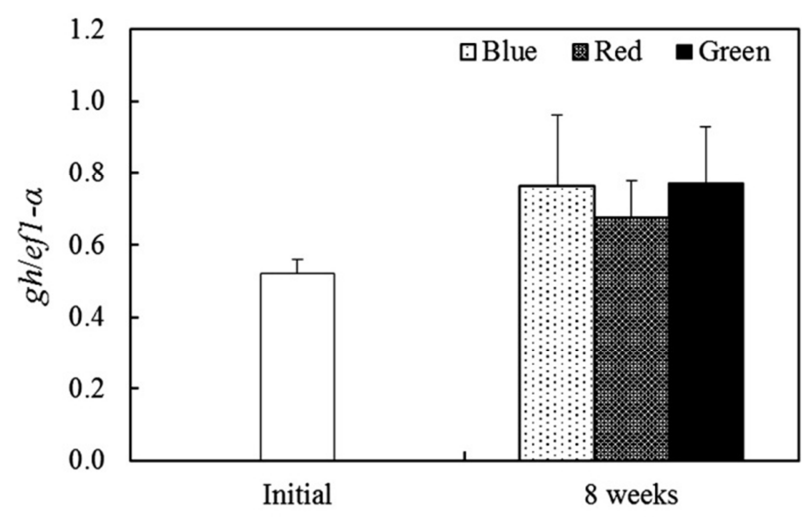

Fig. 3. GH mRNA levels in the pituitary of tiger puffer under different light spectra conditions (blue, red and green). Means represented by different letters are significant $(P<0.05)$. Values are mean \pm SEM.

other groups at 8 weeks (Fig. 2A). The $s s 2$ mRNA was showed similar expression pattern with $s s 1$ mRNA and red light condition was observed higher expression than other groups at 8 weeks (Fig. 2B). The $s s 3$ mRNA was observed more increased expression in blue light condition than other experimental groups at 8 weeks (Fig. 2C). In pituitary, $g h$ mRNA was showed no specific expression between the three groups at 8 weeks (Fig. 3).

\section{DISCUSSION}

Recently, characteristics of adaptive physiology of fish in rearing environmental factors apply to aquaculture. We discuss about information of adaptive physiology of fish in light spectra. Effect of light spectra on the physiological actions (growth, feeding, stress response and reproduction) have been studied in teleost fish (Volpato \& Barreto, 2001; Blanco-Vives et al., 2010; Bapary et al., 2011; Volpato et al., 2013). Especially, effect of light spectra on the somatic growth were announced from some fish. For instance, BW and TL of barfin flounder were increased when reared under green or blue (short wavelength) light conditions and fish growth of red group was remain behind than other groups (Yamanome et al., 2009). Also, green or blue wavelength 
was reported to the positive effect on the fish growth via haddock (Downing, 2002), crucian carp, Chinese sleeper (Ruchin, 2004), olive flounder (Ko \& Park, 2012) and rock fish (Shin et al., 2015). Based on these results, we performed study of light spectra effect on the growth of tiger puffer. Tiger puffer was reared in different light conditions (blue, green and red) for 8 weeks and showed better somatic growth when reared under green light condition. However, reared tiger puffer under red light condition was shown slower growth than other experimental groups. In contrast to our results, rainbow trout showed negative impact on growth performance when rearing under blue light condition (Karakatsouli et al., 2007) and yellow light was efficiently induced the mean weight (Heydarnejad et al., 2013). These different results were suggest that the light spectra represents a species specific effect in fish growth, because preferred wavelength was different for each fish species.

Nevertheless, physiological mechanism of light spectra with growth of fish is still unclear and hardly study. Therefore we investigated changes of weight gain, feed efficiency and growth-related genes expression ( $s s 1, s s 2$, and $s s 3)$ under different light spectra conditions. In generally, SS is well known growth hormone-inhibiting hormone (GHIH) and released in hypothalamus (Sheridan \& Kittilson, 2004; Klein \& Sheridan, 2008). This hormone is inhibited GH secretion in pituitary gland and shows a negative effect on the growth in goldfish (Cook et al., 1984) and orange-spotted grouper (Wang et al., 2014). Furthermore, SS is related to feeding behavior and digestion in fish. In rainbow trout, food conversion was significantly reduced by SS implantation (Very et al., 2001). In contrast with SS, GH is released hormone in pituitary and it has ability of somatic growth control with many biological actions including appetite, osmoregulation and reproduction in teleost fish (Tatsuta \& Hirano, 1993; Mingarro et al., 2002; Kim et al., 2015). In our presents, weight gain and feed efficiency were higher in green light condition, but in red light condition weight gain and feed efficiency were low. The $s s 1$ and $s s 2$ genes of brain were showed high expression when reared under red light condition and its expression were low when reared under green light condition. Therefore, we present results suggest that light spectra were acts as controller of ss gene expression regulation and this ss gene expression will have an effect on the feeding behavior and digestion in fish. However, retardation of $g h$ expression in pituitary was not observed and showed no different expression between experimental groups. In different light conditions (blue, green and red), yellowtail clownfish $g h$ mRNA expression was more higher under green and blue light conditions than under red light condition and induced higher growth rate (Shin et al., 2012). These data were indicate that light spectra affects in endocrine system associated with growth. Although, our present was not confirmed difference of $g h$ expression in pituitary, but $g h$ expression in red light condition was tended to lower than blue and green light conditions. We suggest that ss genes are affect directly or indirectly on the $g h$ expression and further studies are required to relationship of $s s$ with $g h$ genes in tiger puffer.

In this study, green light condition induces higher somatic growth and reducing expression $s s 1$ and $s s 2$ in the brain, but, red light condition is conflicting results with somatic growth and $s s 1$ and $s s 2$ expression. It suggest that red wavelength affects in growth retardation by promoting activation of ss expression. Therefore, artificial green light wavelength is suggest more effective on the growth stimulation than red light wavelength in tiger puffer aqua-farm system, but further studies are needed to clarify the mechanism of light spectra with growth endocrine system.

\section{ACKNOWLEDGEMENTS}

This research was supported by the Basic Science Research Program through the National Research Foundation of Korea (NRF) funded by the Ministry of Education, Science and Technology (2012R1A6A3A04041089). 


\section{REFERENCES}

Bapary, MAJ, Amin, MN, Takeuchi Y, Takemura A (2011) The stimulatory effects of long wavelengths of light on the ovarian development in the tropical damselfish, Chrysiptera cyanea. Aquaculture 314:188-192.

Blanco-Vives B, Villamizar N, Ramos J, Bayarri MJ, Chereguini O, Sánchez-Vázquez FJ (2010) Effect of daily thermo-and photo-cycles of different light spectrum on the development of Senegal sole (Solea senegalensis) larvae. Aquaculture 306:137-145.

Boeuf G, Le Bail PY (1999) Does light have an influence on fish growth?. Aquaculture 177:129-152.

Cook AF, Peter RE (1984) The effects of somatostatin on serum growth hormone levels in the goldfish, Carassius auratus. Gen Com Endocrinol 54:109-113.

Downing G (2002) Impact of spectral composition on larval haddock, Melanogrammus aeglefinus L., growth and survival. Aquacult Res 33:251-259.

Henne JP, Watanabe WO (2003) Effects of light intensity and salinity on growth, survival, and whole-body osmolality of larval southern flounder Paralichthys lethostigma. J World Aquac Soc 34:450-465.

Heydarnejad MS, Parto M, Pilevarian AA (2013) Influence of light colours on growth and stress response of rainbow trout (Oncorhynchus mykiss) under laboratory conditions. J Anim Physiol Anim Nutr 97:67-71.

Hur SW (2011) Characterization of cholecystokinin and mucous-secreting goblet cell in longtooth grouper, Epinephelus bruneus. Doctoral dissertation, Jeju National University, Jeju.

Karakatsouli N, Papoutsoglou ES, Sotiropoulos N, Mourtikas D, Stigen-Martinsen T, Papoutsoglou SE (2010) Effects of light spectrum, rearing density and light intensity on growth performance of scaled and mirror common carp Cyprinus carpio reared under recirculating system conditions. Aquacult Eng 42:121-127.
Karakatsouli N, Papoutsoglou SE, Pizzonia G, Tsatsos G, Tsopelakos A, Chadio S, Kalogiannis D, Dalla C, Polissidis A, Papadopoulou-Daifoti Z (2007) Effects of light spectrum on growth and physiological status of gilthead seabream Sparus aurata and rainbow trout Oncorhynchus mykiss reared under recirculating system conditions. Aquacult Eng 36:302-309.

Kim BH, Lee CH, Hur SW, Hur SP, Kim DH, Suh HL, Lee YD (2013) Long photoperiod affects gonadal development in olive flounder Paralichthys olivaceus. Dev Reprod $17: 241$.

Kim JH, Leggatt RA, Chan M, Volkoff H, Devlin RH (2015) Effects of chronic growth hormone overexpression on appetite-regulating brain gene expression in coho salmon. Mol Cell Endocrinol 413:178-188.

Kissil GW, Lupatsch I, Elizur A, Zohar Y (2001) Long photoperiod delayed spawning and increased somatic growth in gilthead seabream (Sparus aurata). Aquaculture 200:363-379.

Klein SE, Sheridan MA (2008) Somatostatin signaling and the regulation of growth and metabolism in fish. Mol Cell Endocrinol 286:148-154.

Ko KR, Park YS (2012) Research on the difference in growth of flatfish in accordance with color lighting. Journal of Korean Society of Color Studies 26:17-23.

Migaud H, Davie A, Taylor JF (2010) Current knowledge on the photoneuroendocrine regulation of reproduction in temperate fish species. J Fish Biol 76:27-68.

Mingarro M, de Celis SVR, Astola A, Pendòn C, Valdivia MM, Pérez-Sánchez J (2002) Endocrine mediators of seasonal growth in gilthead sea bream (Sparus aurata): the growth hormone and somatolactin paradigm. Gen Comp Endocrinol 128:102-111.

Ruchin AB (2004) Influence of colored light on growth rate of juveniles of fish. Fish Physiol Biochem 30:175178.

Sheridan MA, Kittilson JD (2004) The role of somatostatins 
in the regulation of metabolism in fish. Comp Biochem Physiol B 138:323-330.

Shin HO, Hoe MA, Heo G (2015) The effect of LED light wavelength on the growth of fingerling Sebastes inermis. J Kor Soc Fish Technol 51:179-187.

Shin HS, Lee J, Choi CY (2012) Effects of LED light spectra on the growth of the yellowtail clownfish Amphiprion clarkii. Fish Sci 78:549-556.

Simensen LM, Jonassen TM, Imsland AK, Stefansson SO (2000) Photoperiod regulation of growth of juvenile Atlantic halibut (Hippoglossus hippoglossus L.). Aquaculture 190:119-128.

Taylor JF, Migaud H, Porter MJR, Bromage NR (2005) Photoperiod influences growth rate and plasma insulinlike growth factor-I levels in juvenile rainbow trout, Oncorhynchus mykiss. Gen Com Endocrinol 142:169185.

Very NM, Knutson D, Kittilson JD, Sheridan MA (2001) Somatostatin inhibits growth of rainbow trout. J Fish Biol 59:157-165.

Villamizar N, Blanco-Vives B, Migaud H, Davie A, Carboni S, Sanchez-Vazquez FJ (2011) Effects of light during early larval development of some aquacultured teleosts: a review. Aquaculture 315:86-94.

Villamizar N, García-Alcazar A, Sánchez-Vázquez FJ (2009) Effect of light spectrum and photoperiod on the growth, development and survival of European sea bass (Dicentrarchuslabrax) larvae. Aquaculture 292:80-86.

Volpat GL, Barreto RE (2001) Environmental blue light prevents stress in the fish Nile tilapia. Braz J Med Biol Res 34:1041-1045.

Volpat GL, Bovi TS, de Freitas RH, da Silva DF, Delicio HC, Giaquinto PC, Barreto RE (2013) Red light stimulates feeding motivation in fish but does not improve growth. PloS one 8:e59134.

Wang B, Qin C, Zhang C, Jia J, Sun C, Li W (2014) Differential involvement of signaling pathways in the regulation of growth hormone release by somatostatin and growth hormone-releasing hormone in orange-spotted grouper (Epinephelus coioides). Mol Cell Endocrinol 382:851859.

Yamanome T, Mizusawa K, Hasegawa EI, Takahashi A (2009) Green light stimulates somatic growth in the barfin flounder Verasper moseri. J Exp Zool A 311:73-79. 